\title{
AN EXPERIMENTAL STUDY OF EMISSION AND COMBUSTION CHARACTERISTICS OF MARINE DIESEL ENGINE WITH FUEL INJECTOR MALFUNCTIONS
}

Jerzy Kowalski, Ph. D.

Gdynia Maritime University, Poland

\begin{abstract}
The presented paper shows the results of the laboratory study on the relation between chosen malfunctions of a fuel injector and composition of exhaust gas from the marine engine. The object of research is a marine 3-cylinder, four-stroke, direct injection diesel engine with an intercooler system. The engine was loaded with a generator and supercharged. The generator was electrically connected to the water resistance. The engine operated with a load between $50 \mathrm{~kW}$ and $250 \mathrm{~kW}$ at a constant speed. The engine load and speed, parameters of the turbocharger, systems of cooling, fuelling, lubricating and air exchange, were measured. Fuel injection and combustion pressures in all cylinders of the engine were also recorded. Exhaust gas composition was recorded by using a electrochemical gas analyzer. Air pressure, temperature and humidity were also recorded. Emission characteristics of the engine were calculated according to ISO 8178 standard regulations. During the study the engine operated at the technical condition recognized as „working properly" and with simulated fuel injector malfunctions. Simulation of malfunctions consisted in the increasing and decreasing of fuel injector static opening pressure, decalibration of fuel injector holes and clogging 2 neighboring of 9 fuel injector holes on one of 3 engine cylinders.
\end{abstract}

Keywords: marine diesel engine, exhaust gas composition, toxic emission, laboratory investigation, fuel injector malfunctions

\section{INTRODUCTION}

By the end of the $20^{\text {th }}$ century the main development directions of piston engines were fuel consumption reduction and increase of the structure reliability. Development in this direction is limited due to fuel heating value. Fuel consumption reduction of the internal combustion engines also leads to a reduction of emission of chemical compounds containing carbon and hydrogen. Fuel quality improvement and reduction of sulfur content in fossil fuels also leads to reduction of the emission of sulfur compounds into the atmosphere. Piston engines emit considerable amounts of compounds of the group of nitric oxides $\left(\mathrm{NO}_{\mathrm{x}}\right)$, which result from oxidation of nitrogen contained in the charging air. Since the beginning of the 21st century, the development of piston engines has been determined by limiting regulations of volatile toxic compounds emission. In the case of onboard operated engines, in 1998 year, International Maritime Organization (IMO) introduced regulations on limitation of $\mathrm{NO}_{\mathrm{x}}$ emission for engines installed on ships after 2001 year with nominal power above $130 \mathrm{~kW}$ [1], [2].

It should be noted that the above mentioned limitations relate to newly constructed engines, whereas over $50 \%$ of fleet consists of ships older than 15 years (over 42,5 thousand ships above 100 gross tonnage) [3]. Owners of the mentioned ships are not obliged to control $\mathrm{NO}_{\mathrm{x}}$ emission. Sea-going vessels usually have one or more piston engines installed for propulsion (main engine propulsion). They are usually large, low-speed, two-stroke engines or smaller, mediumspeed, four-stroke engines. The ships are fitted also with engines driving power generators. In this case practically only medium-speed, four-stroke engines are applied. Steam or gas turbines are less frequently used. In the oldest ships diesel engines with mechanically controlled direct fuel injection and turbocharged, were used.

Rational onboard engines operation consists in reparation or adjustment only in the case of observing markedly deviations of diagnostic signals from their nominal values. Such approach reduces operation cost, however, causes a significant increase of toxic compounds emissions and fuel consumption. For this reason, to introduce changes in the organization of marine engine operation, is necessary. However, the mentioned changes must be preceded by a determination of emission characteristics of toxic compounds for engines operating with malfunctions of functional systems.

It should be noted that relatively few results of experimental research concerning emission characteristics of marine diesel engines with mechanically controlled fuel injection, conducted in the past decade, are available. This is due to 
high cost of the experiment. It should be noted that main propulsion engines generate nominal power of about 5 to $20 \mathrm{MW}$, and electric power generator engines of about 200 to $1000 \mathrm{~kW}$. Such large nominal power of engines causes fuel consumption measured in tons per hour.

Sarvi et al. [4], [5], [6] present emission characteristics of a large, medium-speed diesel engine with parameters similar to those of marine engines. Desantes et al. [7], [8] show influence of fuel injection characteristics on emission characteristics and parameters of combustion in one-cylinder engine. Weiser, in his doctorate thesis [9] presents results of direct measurements on 9-cylinder medium-speed engine, and Cooper [10] presents emission characteristics from chosen ships. More detailed data about the influence of fuel injection pressure are available from [12] and [13]. Both the studies present optical measurements of fuel spray process in engine cylinder by schlieren? photography technique and particle image velocimetry. Kyriakides et al. [14] present a model of heavy fuel spray atomization for marine diesel engine, and Danov [15] presents a model describing combustion parameters in a large marine diesel engine.

Lack of new research activities concerning the impact of marine diesel engine malfunctions on emissions induced this author to undertake research on the issue. This paper presents the results of laboratory tests on the effects of selected fuel injector malfunctions on the level of emission. The fuel injector malfunctions are obtained by decreasing and increasing the opening pressure of the fuel injector and using the injector with decalibrated and clogged holes.

\section{LABORATORY TEST STAND AND PROCEDURE}

The study were carried out by using an AL25/30 CegielskiSulzer marine, 3-cylinder, four-stroke, direct - injection diesel engine with an intercooler system, installed in the Laboratory of Internal Combustion Engines, Gdynia Maritime University. The engine was loaded with a generator electrically connected to the water resistance and supercharged by a VTR 160 BrownBoveri turbocharger. During the tests the engine was fuelled with diesel oil of the properties presented in Tab.1, and operated at the constant speed equal to $750 \mathrm{rpm}$. The fuelling system of the engine consisted of a Bosch mechanically controlled fuel pumps connected to injectors with multi-hole nozzles. This type of engine is commonly used as a electric power generator or main propulsion system with controllable pitch propeller [11]. Engine load and speed, parameters of the turbocharger, systems of cooling, fuelling, lubricating, and air exchange, were measured. The composition of exhaust gas was also recorded by using electrochemical gas analyzer with infrared carbon dioxide sensor. Air pressure, temperature and humidity were also recorded by laboratory equipment. All the mentioned results were recorded with one-second sampling time. Injection and combustion pressures in all cylinders of the engine were also recorded. A schematic diagram of the laboratory test stand is presented in Fig.1. Values of the most important engine parameters are given in Tab.2.
Tab.1 Diesel fuel oil properties

\begin{tabular}{|l|r|r|}
\hline \multicolumn{1}{|c|}{ Parameter } & Value & Unit \\
\hline Density at $15^{\circ} \mathrm{C}$ & 827,3 & $\mathrm{~kg} / \mathrm{m}^{3}$ \\
\hline Kinematic viscosity at $40^{\circ} \mathrm{C}$ & 2,636 & $\mathrm{~mm}^{2} / \mathrm{s}$ \\
\hline Cetane number & 53,2 & - \\
\hline Sulfur content & 3,8 & $\mathrm{mg} / \mathrm{kg}$ \\
\hline
\end{tabular}

Tab.2. Parameters of the Al25/30 engine

\begin{tabular}{|l|r|r|}
\hline \multicolumn{1}{|c|}{ Parameter } & Value & \multicolumn{1}{c|}{ Unit } \\
\hline Max. electric power & 250 & $\mathrm{~kW}$ \\
\hline Rotational speed & 750 & $\mathrm{rpm}$ \\
\hline Cylinder number & 3 & - \\
\hline Cylinder diameter & 250 & $\mathrm{~mm}$ \\
\hline Stroke & 300 & $\mathrm{~mm}$ \\
\hline Compression ratio & 12,7 & - \\
\hline
\end{tabular}

The experimental study consists of 5 stages, of 3 observations each, at different simulated malfunctions of the fuel injector installed in $2^{\text {nd }}$ cylinder of the engine. During each start of observation, the engine was loaded up to the maximum load equal to $250 \mathrm{~kW}$ measured as an electric power of the generator, and, after stabilization of exhaust gas temperature behind the turbine, engine operating parameters were recorded for 3 to 5 minutes. During this time, injection and combustion pressures in all cylinders of the engine were recorded for 16 full turnover of engine shaft with intervals equal to $0,5^{\circ}$.

Then the load of the engine was decreased by $10 \mathrm{~kW}$, and after stabilization of exhaust gas temperature behind the turbine, engine operating parameters were recorded again. The observation was continued with loads up to $50 \mathrm{~kW}$ at a constant speed. The engine did not work under the load of $190 \mathrm{~kW}$ due to resonance vibrations. Stages of experiment were set as follows:

- $\quad 1^{\text {st }}$ stage - during operation of the engine assumed as "working properly",

- $\quad 2^{\text {nd }}$ stage - during operation of the engine with opening pressure decreased to $15 \mathrm{MPa}$,

- $\quad 3^{\text {rd }}$ stage - during operation of the engine with opening pressure increased to $35 \mathrm{MPa}$,

- $\quad 4^{\text {th }}$ stage - during operation of the engine with a nozzle with 8 holes of $0,375 \mathrm{~mm}$ diameter,

- $\quad 5^{\text {th }}$ stage - during operation of the engine with a nozzle with 2 , out of 9 , neighboring holes clogged.

Values of the parameters of fuel injector in $2^{\text {nd }}$ cylinder are presented for the considered stages in Tab.3.

Tab.3. Parameters of fuel injector in 2nd cylinder

\begin{tabular}{|l|r|r|r|r|r|}
\hline & \multicolumn{6}{|c|}{ Stage } \\
\hline Parameter and unit & \multicolumn{1}{|c|}{1} & \multicolumn{1}{|c|}{3} & \multicolumn{1}{c|}{4} & \multicolumn{1}{c|}{5} \\
\hline Number of holes & 9 & 9 & 9 & 8 & $9-2=7$ \\
\hline Hole diameter [mm] & 0,325 & 0,325 & 0,325 & 0,375 & 0,325 \\
\hline Opening pressure [MPa] & 25 & 15 & 35 & 25 & 25 \\
\hline
\end{tabular}




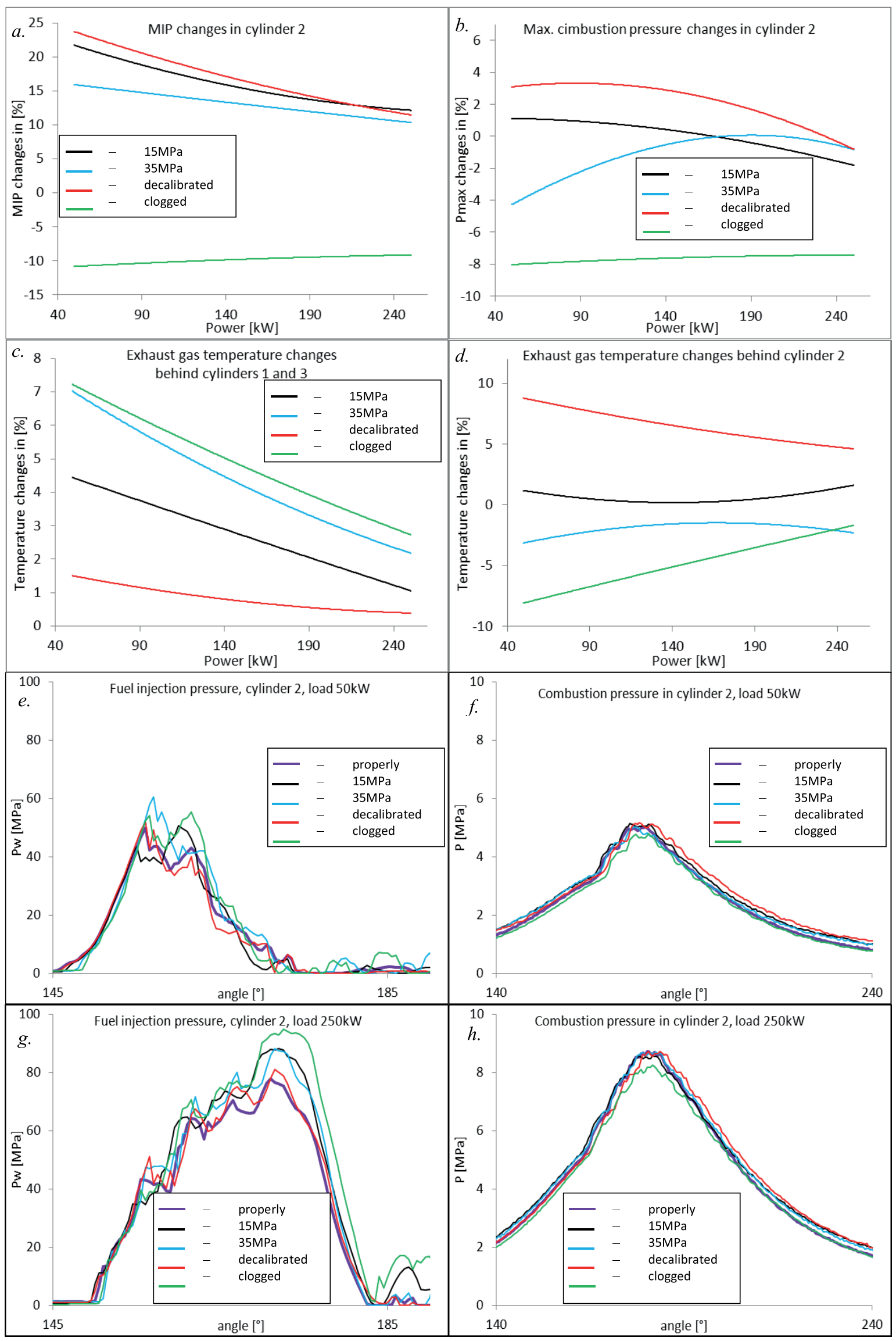

Fig.2. Changes in thermodynamic parameters of gas mixture in engine cylinders 

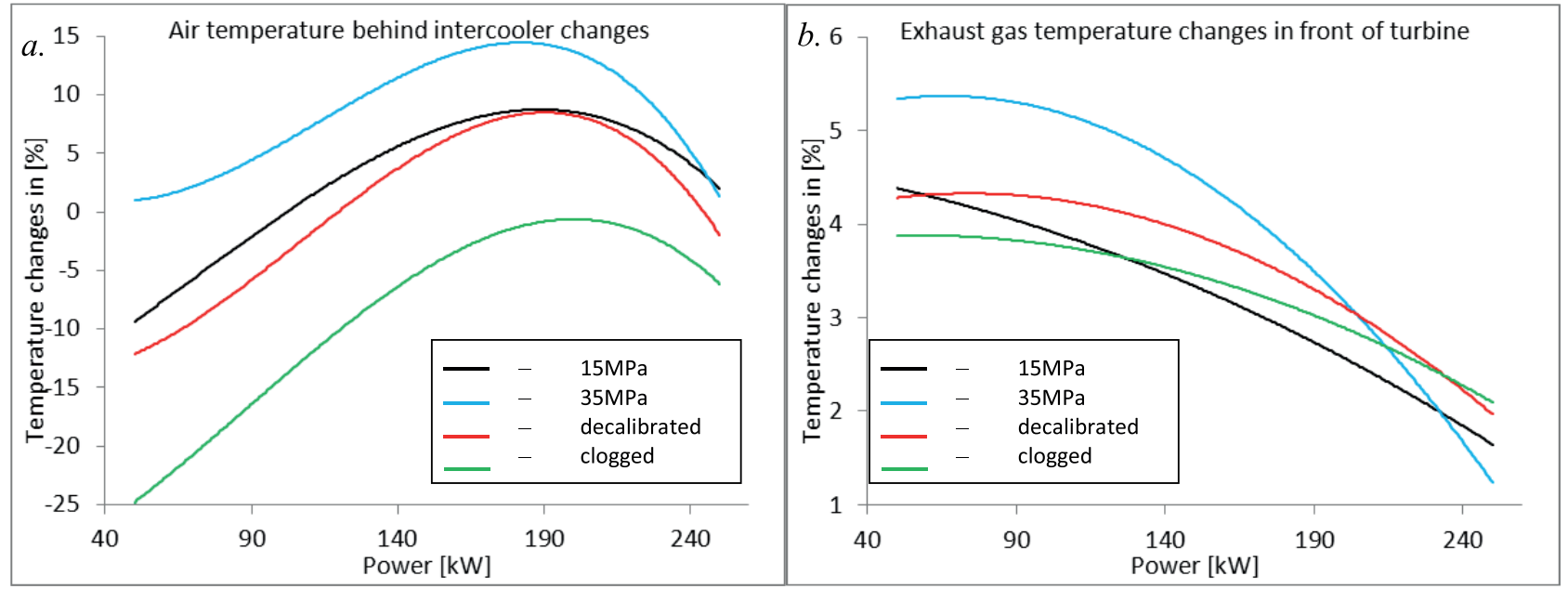

Fig.3. Changes in thermodynamic parameters of air and exhaust gas

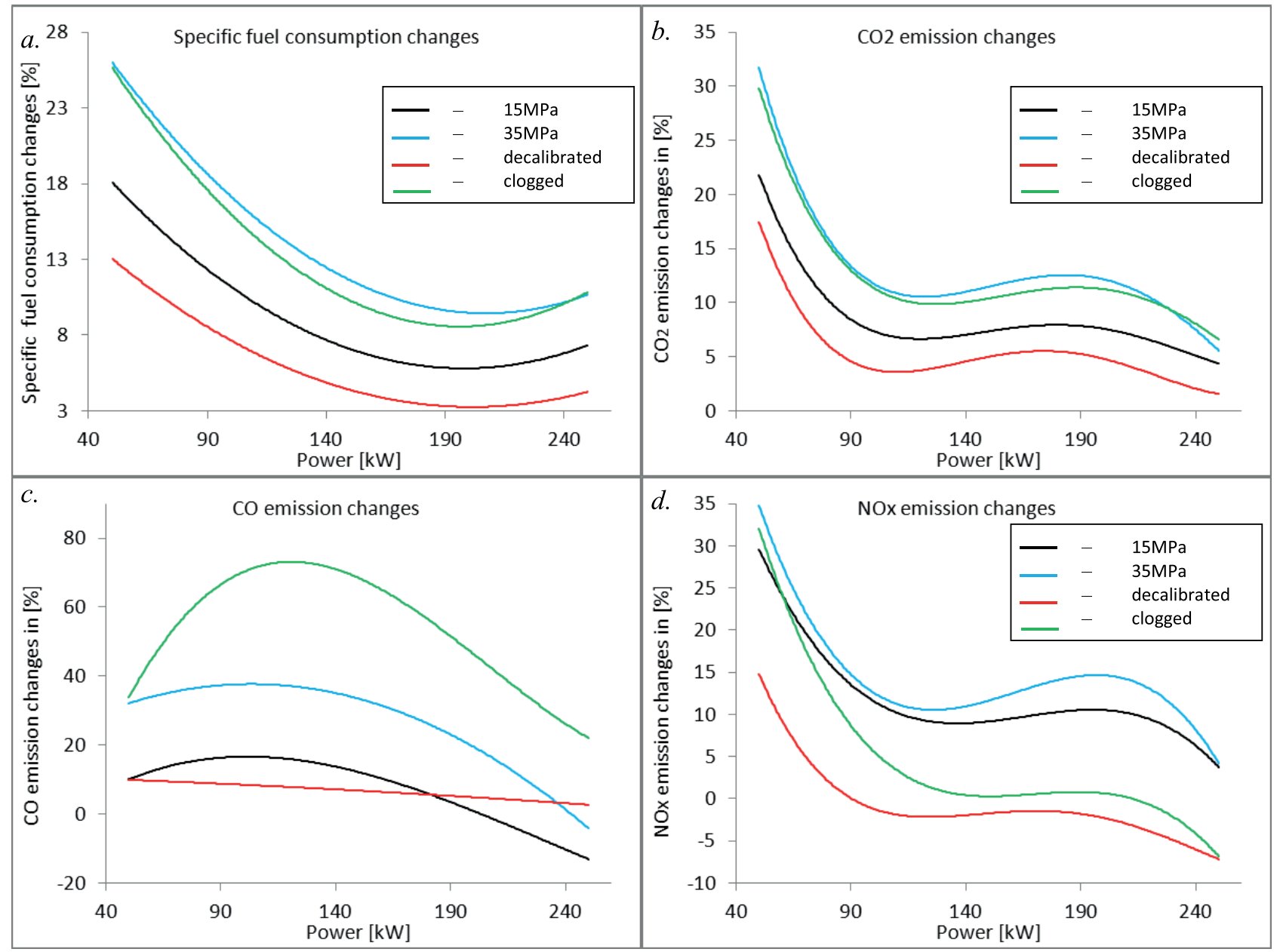

Fig.4. Changes in specific fuel consumption and emission characteristics 


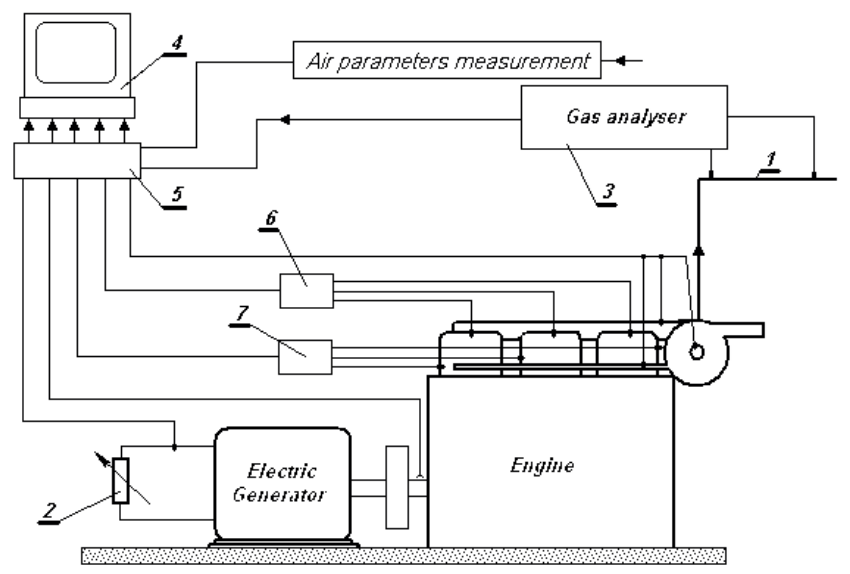

Fig.1. Schematic diagram of the laboratory test stand: 1 - exhaust duct, 2 - water resistance, 3 - gas analyzer, 4 - computer, 5 - A/C converter, 6 - combustion pressure indicator, 7 -injection pressure indicator

\section{RESULTS AND DISCUSSION}

Fig.2, 3 and 4 present the results of the laboratory study. Fig. 2 presents pressure and temperature changes of fuel and combustion mixture in engine cylinders.

Fig. 3 presents changes in thermodynamic parameters of air and exhaust gas, and Fig. 4 presents changes in fuel consumption and emission characteristics. All the mentioned changes in parameters were compared to those of the engine recognized as "working properly". Emission characteristics were obtained from laboratory measurements and calculations according to ISO 8178 regulations [16]. All the presented results are mean values achieved from the performed observations.

\section{DECREASED OPENING PRESSURE OF FUEL INJECTOR}

The second stage of the experimental study is based on the reduction of the static opening pressure of fuel injector at $2^{\text {nd }}$ cylinder in accordance to the values presented in Tab.2. Such malfunction can be caused by damage of the fuel injector spring.

Average values of the results obtained for this stage of the study are represented by black lines. Fig.2e and Fig.2g present average values of fuel injection pressure characteristics for 48 full rotations of engine shaft, the fuel pressure increase along with the progress of the fuel injection process. The results are obvious and consistent with results presented e.g. in [17]. It should be noted that in the case of the operation of the "working properly" engine (violet line) at low loads, fuel pressure is larger at the start of the injection process. An increase of fuel pressure leads to the increase of the fuel reach in the cylinder and the reduction of the average diameter of injected fuel droplets [18], [19]. In the case of low engine load the phenomena are not desirable due to the low concentration of fuel vapour in cylinder volume. Injection pressure drop causes slight lengthening of the combustion process in the engine at large loads. According to the results presented in Fig.2a and Fig.2b, the injection pressure decrease does not cause significant change of maximum combustion pressure. Extension of the combustion process increases the mean indicated in-cylinder pressure (MIP) by $20 \%$ at low loads. According to the data presented in Fig.2c and Fig.2d, the decrease of the opening pressure in fuel injector does not change the temperature of the exhaust gas behind the 2nd cylinder, however, it increases temperature of the exhaust gas from other cylinders. For this reason mean temperature of exhaust gas in front of the turbine (Fig.3b) slightly increases. As a result, the amount of energy supplied to the turbine also increases. This causes supplying larger amount of air to the cylinders. A drop of the air temperature at low engine loads presented in Fig.3a, promotes delivering more air into the cylinders. These phenomena are correlated with an increase of fuel droplets reach in the cylinder and deteriorate combustion conditions. The effect of this is a significant increase of fuel consumption (Fig. $4 \mathrm{a}$ ) by up to $18 \%$. The increase of the amount of air and fuel causes the exhaust gas amount to increase. In Fig.4b, Fig.4c and Fig.4d changes of the engine emission characteristics are presented. According to the presented results the increase of the fuel consumption at low engine loads also causes $20 \%$ increase of carbon dioxide $\left(\mathrm{CO}_{2}\right)$ emission.

There is also the increase of nitric oxides $\left(\mathrm{NO}_{\mathrm{x}}\right)$ emission by $30 \%$ at low engine loads. This is due to the increase of combustion temperature in other cylinders and the increase of the amount of air supplied to the engine.

According to the presented results a drop of fuel injector opening pressure on one of the cylinders is clearly visible only during the engine operation at low loads.

The mentioned malfunction causes significant increase in fuel consumption and the increase in amount of $\mathrm{CO}_{2}$ and $\mathrm{NO}_{\mathrm{x}}$ emission.

\section{INCREASED OPENING PRESSURE OF FUEL INJECTOR}

In the $3^{\text {rd }}$ stage of the laboratory research the static opening pressure of the fuel injector on the $2^{\text {nd }}$ cylinder, was increased. Such malfunction may be caused by improper adjustment of the fuel injector spring. Changes of engine operating parameters for the "working properly" engine are presented in blue in the graphs. According to Fig.2e and Fig.2g the considered malfunction causes the increase of fuel injection pressure during whole injection process in all considered engine loads. Fuel injection time is slightly longer too. The obtained results are consistent with [20] and [21]. It causes a fuel consumption increase (Fig.4a) especially at low engine loads. It should be noted that the increase of fuel consumption is in this case the largest among all considered engine malfunctions.

The effect of this is $10-15 \%$ MIP increase at all considered engine loads (Fig.2a). According to the data presented in Fig.2, the increase of the opening pressure of fuel injector causes a slight drop of the maximum combustion pressure for engine at low loads and a slight decrease in temperature of the exhaust gas from the $2^{\text {nd }}$ cylinder.

The temperature increase of exhaust gas from other engine cylinders, particularly apparent at low engine loads, is visible. 
As for the case of fuel injector opening pressure drop, the temperature of exhaust gas in front of turbine increases (Fig.3b).

The result of the simulated malfunction is a combustion deterioration manifested by an increased carbon monoxide (CO) emission by up to $40 \%$ for the engine operating at partial loads (Fig.4c). According to the results presented in Fig.4a, the increase of the opening pressure of the fuel injector causes a $10-25 \%$ increase of the fuel consumption and a 5-30\% increase of the $\mathrm{CO}_{2}$ emission (Fig.4b). The result of the increase of the fuel consumption is qualitatively consistent with the results presented in [22].

The deterioration of the combustion process in a damaged cylinder and the change of the performance characteristics of the other cylinders can cause a combustion temperature increase, which is manifested by the increase of the $\mathrm{NO}_{\mathrm{x}}$ emissions (Fig.4d).

The considered malfunction can be recognized in practice, during onboard operation, by measuring the $\mathrm{CO}, \mathrm{CO}_{2}$ and $\mathrm{NO}_{\mathrm{x}}$ emissions at low engine loads. The described malfunction causes a fuel consumption increase at all considered engine loads.

\section{DECALIBRATED FUEL INJECTOR HOLES}

During this stage of the experimental study the fuel injector nozzle in the $2^{\text {nd }}$ cylinder was changed. The changed injector nozzle parameters are presented in Tab.2. The change results in the increase of the summary cross section area of nozzle holes by $18.3 \%$. The results obtained in the stage are represented by the red line. The expected result should be a reduction of the fuel injection time, resulting from the increase of the cross section area of nozzle holes and the increase of the average droplet diameter of injected fuel [22]. According to the values presented in Fig.2e and Fig.2g, the characteristic of the fuel injection pressure experiences no significant change. This is probably due to the insufficient change in diameter of the injector holes. According to the results given in Fig.2f and Fig.2h, the increase of the mean diameter of the fuel droplets causes the increase of combustion time. The result of this is MIP increase by $14-23 \%$ (Fig.2a) for small changes of the maximum injection pressure (Fig.2b). The abnormal shape of the fuel injection increases fuel consumption, but only at the low engine loads (Fig.4a). The increase of the mean fuel droplet diameter increases the fuel evaporation time, which may cause the combustion temperature to increase. The evidence of this situation is an increase in NOx emission (Fig.4d). The presented temperature changes and longer combustion time make the exhaust gas temperature increasing behind the 2 nd cylinder too (Fig.2d). The effect of the fuel consumption increase and the increase of the exhaust gas temperature behind the 2nd cylinder is a slight increase of the exhaust gas temperature in front of the turbine, which is a similar result to those obtained in the 2nd and 3rd stage of the research (Fig.3b).

The presented malfunction causes a $\mathrm{CO}_{2}$ emission increase at low engine loads (Fig.4b). This is a direct consequence of the fuel consumption increase. It should be noted that a decalibration of the fuel injector holes does not cause any significant changes in the $\mathrm{CO}$ emission characteristics (Fig.4c).

From the assessment of the onboard engine operation it can be concluded that the presented change of the fuel injector parameters causes a significant increase of the exhaust gas temperature behind the cylinder, the increase of $\mathrm{NO}_{\mathrm{x}}$ and $\mathrm{CO}_{2}$ emissions and of the fuel consumption. The results are clearly visible in the low engine load conditions.

\section{CLOGGED FUEL INJECTOR HOLES}

The last considered malfunction is clogging the neighboring 2 , out of 9 , holes of the fuel injector nozzle on the $2^{\text {nd }}$ cylinder. The "baking" of the injector nozzle holes is a common malfunction in onboard operational practice. The average results for this malfunction are represented by green lines.

The clogging of the injector nozzle causes, according to the data presented in Fig.2e and Fig.2g, the decrease of the summary cross section area of the fuel injector holes. The effect of this is the increase of the fuel injection pressure and the extension of time of the fuel injection into the cylinder. The increase of the fuel injection pressure causes a drop of mean diameter of the fuel droplets [18], [19] and the increase of the fuel richness in the cylinder [17]. It should be pointed out that by clogging 2 neighboring holes of the fuel injector some areas of the combustion chamber are left with a fuel deficiency. According to the results from Fig. 2 a and Fig.2b, it causes 10\% MIP decrease and $8 \%$ decrease of the maximum combustion pressure at all considered loads of the engine.

The effect of the decreased combustion pressure is clearly visible in Fig. $2 \mathrm{f}$ and Fig. $2 \mathrm{~h}$ too. Inaccurate fuel and air mixing is a cause of an incomplete combustion in cylinder. According to the results given in Fig.4c it causes even $70 \%$ increase of the $\mathrm{CO}$ emission. The result of an insufficient combustion is a drop of the exhaust gas temperature behind the cylinder (Fig.2d), which is visible especially at low engine loads. Power deficiency in the 2 nd cylinder must be compensated by the load increase in the other cylinders. Therefore, the temperature of the exhaust gas from the other cylinders increases (Fig.2c) and the temperature in front of turbine increases too (Fig.3b). Abnormal combustion in the 2 nd cylinder is also a cause of a fuel consumption increase. According to the results presented in Fig.4a, even 25\% increase of fuel consumption at low engine load conditions, followed. Similarly to the previously described cases of malfunction, also in this case a fuel consumption increase results in the increase of $\mathrm{CO}_{2}$ emissions (Fig.4b). The considered malfunction also increases $\mathrm{NO}_{\mathrm{x}}$ emissions at the low engine loads, which is caused by the increase of the combustion process temperature behind the 2 nd cylinder and the increase of the fuel consumption. According to the results given in Fig.4d, the engine operation at high loads effects in $5 \%$ decrease of the $\mathrm{NO}_{\mathrm{x}}$ emission. The reasons for this should be sought in operation of the other engine cylinders at higher loads. Increased loads result in the reduction of the $\mathrm{NO}_{\mathrm{x}}$ emission. 
The discussed malfunction increases fuel consumption and decreases combustion pressure at all considered engine loads. The emission measurements show even $70 \%$ increase of CO emission at medium engine loads and about $30 \%$ increase of $\mathrm{CO}_{2}$ and $\mathrm{NO}_{\mathrm{x}}$ emissions at low engine loads.

\section{CONCLUSIONS}

As a result of the experimental study the following conclusions can be drawn:

1. The decrease of the static opening pressure of the fuel injector in one of the engine cylinders is clearly visible only at low engine loads conditions. The malfunction causes the increase of $\mathrm{CO}_{2}$ and $\mathrm{NO}_{x}$ emission and significantly small changes of $\mathrm{CO}$ emission.

2. The increase of the static opening pressure of the fuel injector in one of the engine cylinders causes the increase of the emissions of the measured gaseous compounds, qualitatively similar to that in the case of the engine operation with the decrease of the static opening pressure of the fuel injector.

3. The increase of the cross-section area of the fuel injector holes in one of the engine cylinders causes the increase of the exhaust gas temperature behind the cylinder with such malfunction and slight temperature fluctuations of the exhaust gas from the other engine cylinders. Emission measurements demonstrated only small changes of the $\mathrm{CO}$ emission and a decrease of the $\mathrm{NO}_{\mathrm{x}}$ emission at high engine load conditions.

4. Clogged fuel injector holes cause the decrease of the combustion pressure in all considered loads of the engine. Emission measurements demonstrated the increase of the CO emission even by up to $70 \%$ at medium engine loads and the increase of the $\mathrm{CO}_{2}$ and $\mathrm{NO}_{\mathrm{x}}$ emission at low engine loads, by up to $30 \%$.

\section{ACKNOWLEDGMENTS}

The project was financially supported by the National Science Centre of Poland ( a grant based on the decision No. DEC-2011/01/D/ST8/07142)

\section{BIBLIOGRAPHY}

1. Revised Marpol Annex VI. Regulations for the Prevention of Air Pollution from Ships. Resolution MEPC.176(58). International Maritime Organization, 2008

2. Technical Code on Control of Emission of Nitrogen Oxides from Marine Diesel Engines. Resolution MEPC.177(58). International Maritime Organization, 2008

3. The world merchant fleet in 2011. Statistics from Equasis, 2012
4. A. Sarvi, C. J. Fogelholm, R. Zevenhoven: Emissions from large-scale medium-speed diesel engines: 1. Influence of engine operation mode and turbocharger, Fuel processing technology 89 (2008), pp. $510 \div 519$

5. A. Sarvi, C. J. Fogelholm, R. Zevenhoven: Emissions from large-scale medium-speed diesel engines: 2. Influence of fuel type and operating mode, Fuel processing technology 89 (2008) , pp. $520 \div 527$

6. A. Sarvi, R. Zevenhoven, Large-scale diesel engine emission control parameters, Energy 35 (2010), pp. 1139 $\div 1145$

7. J.M. Desantes, J. Benajes, S. Molina, C.A. Gonzalez: The modification of the fuel injection rate in heavy-duty diesel engines. Part 1: Effects on engine performance and emissions, Applied Thermal Engineering 24 (2004), pp. $2701 \div 2714$

8. J.M. Desantes, J. Benajes, S. Molina, C.A. Gonzalez: The modification of the fuel injection rate in heavy-duty diesel engines. Part 2: Effects on combustion, Applied Thermal Engineering 24 (2004), pp. $2715 \div 2726$

9. G.A. Weiser: Modelling of Combustion and Nitric Oxide Formation for Medium-Speed DI Diesel Engines: A Comparative Evaluation of Zero- and ThreeDimensional Approaches, Doctors Thesis, Swiss Federal Institute of Technology Zurich, 2001

10. D.A. Cooper: Exhaust emissions from ships at berth, Atmospheric Environment 37 (2003) , pp. $3817 \div 3830$

11. J. Carlton: Marine Propellers and Propulsion, Third Ed., Elsevier Ltd., 2012

12. W. Xiangyi, X. Feng, L. Wang: Experimental Study on Characteristics of Conical Spray and Combustion for Medium Speed D.I. Diesel Engine, SAE Technical Paper 930598, 1993, doi:10.4271/930598

13. T. Sarjovaara, H. Hillamo, M. Larmi, T. Olenius: Optical In-Cylinder Measurements of a Large-Bore MediumSpeed Diesel Engine, SAE Technical Paper 2008-01-2477, 2008, doi:10.4271/2008-01-2477

14. N. Kyriakides, C. Chryssakis, L. Kaiktsis: Influence of Heavy Fuel Properties on Spray Atomization for Marine Diesel Engine Applications, SAE Technical Paper 200901-1858, 2009, doi:10.4271/2009-01-1858

15. S. Danov, A. Gupta: Effect of Sauter Mean Diameter on the Combustion Related Parameters in a Large-Bore Marine Diesel Engine, SAE Technical Paper 1999-01-0224, 1999, doi:10.4271/1999-01-0224

16. ISO8178 regulation. International Organization of Standardization 
17. J.B. Heywood:Internal Combustion Engine Fundamentals, McGraw-Hill, 1988

18. C. D. Rakopoulos, E. G. Giakoumis: Speed and load effects on the availability balances and irreversibilities production in a multi-cylinder turbocharged diesel engine, Applied Thermal Engineering 17 (1997), pp. 299 $\div 313$

19. C. D. Rakopoulos, E. G. Giakoumis: Simulation and analysis of a naturally aspirated IDI diesel engine under transient conditions comprising the effect of various dynamic and thermodynamic parameters, Energy Conversion and Management 39 (1998) pp. 465 $\div 484$

20. J.M. Desantes, J. Benajes, S. Molina, C.A. Gonzalez: The modification of the fuel injection rate in heavy-duty diesel engines. Part 1: Effects on engine performance and emissions, Applied Thermal Engineering 24 (2004), pp. $2701 \div 2714$

21. J.M. Desantes, J. Benajes, S. Molina, C.A. Gonzalez: The modification of the fuel injection rate in heavy-duty diesel engines Part 2: Effects on combustion, Applied Thermal Engineering 24 (2004), pp. $2715 \div 2726$

22. I. Celikten: An experimental investigation of the effect of the injection pressure on engine performance and exhaust emission in indirect injection diesel engines, Applied Thermal Engineering 23 (2003), pp. $2051 \div 2060$

23. K. K. Kuo: Principles of combustion. John Wiley, 2005
CONTACT WITH THE AUTHOR

Jerzy Kowalski

Gdynia Maritime University

Department of Engineering Sciences

Morska 81-87 Street

81-225 Gdynia

Poland

tel.: +48586901331

fax: +48586901399

e-mail: jerzy95@am.gdynia.pl 